RODRIGUES, F., GURSKI, R. (Orgs.). Educação e função paterna. Porto Alegre: Editora da UFRGS, 2008.

\title{
A ESCOLA DA ERA MODERNA: ENTRE A TRANSMISSÃO E A VIGILÂNCIA
}

\author{
Douglas Emiliano Batista ${ }^{*}$
}

Se é possível dizer que a riqueza de um livro - e em particular, de um livro organizado a partir de artigos redigidos por autores singulares, mas que possuem em comum determinado campo de estudos - está assentada na pluralidade das reflexões que dá a público e na relevância delas para a análise dos problemas do nosso tempo, então é preciso reconhecer a preciosa contribuição de Educação e função paterna. O livro oferece, pois, uma expressiva amostra de que o campo de estudos de psicanálise e educação abriga em si possibilidades epistêmicas tão férteis quanto, por vezes, heterogêneas. Ou, para dizê-lo em outras palavras, o livro em tela dá a ver a singularidade das inscrições dos autores e debatedores no horizonte dessa tradição. Afinal de contas, também aí é necessário que cada sujeito adquira aquilo que vem a herdar das reflexões já consumadas, as quais foram principiadas por Freud, o pai da psicanálise (fato que por si só repõe o tema mesmo da função paterna). Nesse sentido, o objetivo desta resenha é o de dar também certa amostra, muito embora se trate de uma "paradoxal" amostra, da irrepetibilidade dos pontos de vista dos autores de Educação e função paterna.

Que os desdobramentos do ideário educacional prevalente na contemporaneidade estejam conduzindo ao pior é algo que não chega a promover dissensão no interior da obra resenhada. Entretanto, saber se esse contemporâneo estado de coisas atinente ao campo educacional (isto é, atinente ao registro da estruturação psíquica elementar, mas também ao registro institucional da escola) é ou não o resultado inelutável daquela educação e também daqueles valores e premissas deslanchados nos primórdios dos tempos modernos, eis algo que acicata o debate.

\footnotetext{
* Bolsista Fapesp. Mestrando FE-USP, membro do LEPSI - Laboratório de Estudos e Pesquisas Psicanalíticas e Educacionais sobre a Infância - IP-FE-USP. E-mail: demilian@uol.com.br
} 
E é no miolo dessa polêmica que, de acordo com Gurski (GURSKI; RODRIGUES, 2008, p. 26), o Iluminismo - ao mesmo tempo que ensejou a superação do dogma religioso - difundiu a reflexividade como fundamento de todo ato humano, o que então obliterou a ordem das certezas produzidas com vestígios do sujeito. Eis que, desde aí, os sujeitos já não puderam mais bancar seus atos a partir de suas experiências, uma vez que o valor da verdade comprovada excedeu toda e qualquer aposta na palavra autorizada desde a subjetividade. No que diz respeito à educação, e mais até, no que toca à transmissão simbólica, a autoridade do mestre de fazer e transmitir a lei se esvaiu, posto que a transmissão moderna - em que a enunciação de uma lei comum deve se impor por si mesma sem a autorização de um mestre, de um pai - sujeitou-se então ao anônimo império da funcionalidade, do utilitarismo. Com isso, paulatinamente elidiram-se, nos tempos modernos, as marcas singulares dos sujeitos que veiculam a transmissão simbólica.

Ainda no tocante a essa questão, Kessler (RODRIGUES, F., GURSKI, R., 2008, p. 39) destaca outra faceta. Segundo o autor, a modernidade, de fato, é mesmo um período histórico em que o arbítrio da autoridade já não desponta como auto-suficiente, posto que a interrogação e a argumentação bem podem ter aí a sua vez: "Sabe-se o quanto a assim chamada modernidade possui como ideal a autonomia, a resistência ao que vem da autoridade" (ibidem, p. 35). Não é então para menos que, desde o Iluminismo, a educação tenha sido posicionada no "lugar princeps de uma utopia", e isso como decorrência direta da importância desde aí conferida ao conhecimento e à reflexividade. Nesse cenário, algo da ordem de uma rebeldia à tradição e à autoridade inegavelmente despontou no horizonte. Eis, pois, que nós - os homens do ocidente - "buscamos ser únicos, originais", relembra o autor, o que, com efeito, implica que cada sujeito agora bem pode desejar inventar o seu "próprio" caminho.

Tal como lembra Cabistani (ibidem, p. 43), a queda da figura patriarcal tradicional está longe de ser algo recente no tempo histórico. Ora, bem, então por que se fala dela amiúde como se se tratasse de fato recentíssimo? Tal queixa sobre o eclipse do patriarcado, de acordo com a autora, não aponta senão para a novela familiar do neurótico. A particularidade, entretanto, é que, por meio da atual novela familiar, o que se almeja inconscientemente é preencher certo lugar "vazio" da função paterna. Isto é, a novela familiar de hoje põe em ato dada nostalgia da estrutura familiar tradicional e na qual era o pai quem encarnava o poder. Mas alerta a autora: a carência do pai no complexo de Édipo difere da 
carência realista do pai. E ao declínio do patriarcado bem pode ter correspondido uma ascensão simbólica do pai (por óbvio, do pai enquanto significante, enquanto metáfora que substitui a presença-ausência da mãe). A autora se refere, assim, a um deslocamento - mais do que a um declínio da função do pai (o que é inclusive ratificado pela multiplicidade das versões do Nome-do-Pai). E mesmo quando é o caso de se presumir que a dita família nuclear transformou-se radicalmente a ponto de hoje ter adquirido um formato matrifocal, mesmo aí o pai costuma possuir a autoridade de uma "segunda instância" (a exemplo das instâncias que estruturam o judiciário): quando a "primeira instância" (a autoridade da mãe) não pode fazer valer sua palavra em face do filho, é pois ao pai a quem se recorre. Nesses termos, pode-se admitir que a palavra materna é aquela que confere eficácia à palavra do pai.

Alves e Molina (ibidem, p. 62) nos lembram ainda que a função paterna ordena e regula a relação mãe-filho ao mesmo tempo em que é ela indicadora das futuras relações socioculturais da criança (ou seja, é indicadora do seu devir). Daí que a linguagem tenha mesmo uma vocação para gerar a diferença subjetiva. Ou seja: a condição "para que o sujeito a advir possa construir a versão da sua história" (ibidem, p. 62) é a transmissão da pré-história significante familiar. Ou, como diz Tavares (ibidem, p. 51), o interjogo entre a "nova versão" e a "velha versão" (e no interior do qual se dá o devir não só do sujeito, mas também da Cultura) se desintegraria sem a imantação do significante do Nome-do-Pai, ou melhor, sem a sua constelação de significantes (constelação que preserva o tesouro mesmo dos significantes). É que uma vez "capturado na matriz lingüístico-social (entre o Nome-do-Pai e o Édipo) resta-lhe [ao sujeito] o problema da origem da verdade que o engendrou" (ibidem, p. 54). Ou, em outras palavras, o sujeito, aí, já não pode senão "pagar" simbolicamente por aquilo que herdou, uma vez que "o encontro do novo surge como corolário de um processo de procura de um significante que responda à interrogação da origem" (ibidem, p. 54). Eis que o novo significante tem necessariamente que se inserir na cadeia de significantes da origem. Mas, para isso, é imprescindível que o sujeito não se encontre escravizado a um saber que originalmente advém tão-somente do Outro (isto é, que só pode ser sustentado pelo Outro do discurso social). E o saber da tradição não opera senão de modo a arremessar o sujeito na mesma posição em que já se encontram os seus antepassados, ou seja, como morto. Eis que a possibilidade da emergência de uma nova significação é, portanto, função da "tentativa de escapar da antecipação da morte, é dar vida ao 
desejo" (ibidem, p. 59). E embora tal escapada não se dê em nome apenas da liberdade subjetiva (como supôs, de modo geral, o Iluminismo), ela, no entanto, permanece cifrada na possibilidade de o sujeito fazer metáfora dos significantes que lhe fundaram. O sujeito, portanto, só vem a engendrar uma significação inédita, irrepetível, na medida em que ela esteja autorizada pelo pai, ou seja, na medida em que o pai de carne e osso seja um transmissor do saber e não o seu suposto detentor (detentor à la Schereber, por exemplo). Daí que a palavra "arte", afinal de contas, designe também "travessura", isto é, possibilidade de criação ou de transgressão à lei do pai. E tal como lembra ainda Rodrigues (ibidem, p. 91) com base em Lacan, também a moderna arte de James Joyce, com efeito, não tinha em vista a complementação da paternidade, mas forjava antes a "sua versão do que pode fazer as vezes da paternidade" (ibidem, p. 91).

Em outra variação do mesmo tema ora destacado orbita a polêmica do estatuto da escola como dispositivo social do Estado Moderno. A exemplo do que assevera Gurski (ibidem, p. 17-18), na educação medieval a autoridade do mestre - ou da coletividade de adultos sobre o aluno se limitava ao ensino, não se constituindo como autoridade disciplinar. Já na escola moderna, primava-se pela vigilância e pelo controle exercido sobre o corpo de cada aluno. A escola, como lugar fechado, lançava mão de dispositivos didáticos pautados pela repetição e pela obediência, com vistas ao desenvolvimento de aptidões (eis que posteriormente à hostilização que os moralistas do XVII levaram a cabo e que tinha por objeto a educação familiar, a escola e o Estado se constituíram como parceiros da família com o fito de desenvolver tais aptidões). Entretanto, em meio ao "movimento de 'iluminar' a família, a escola passou a tomar o lugar desta com legitimidade social" (ibidem, 19), o que, a um só tempo, provocou a erosão da autoridade parental e a perda da especificidade do ato educacional por parte da escola: esta última se viu, desde então, constrangida ao engodo de fazer suplência das degradadas funções parentais.

Já de acordo com Kessler (ibidem, p. 32), a escola - a moderna, mas nem sempre a contemporânea - de fato é essa instituição que exige da criança "sentar, ficar quieta e prestar atenção" (ibidem, p. 33). E o ideário de universalização do acesso à educação, por certo, não poderia senão ter incrementado ainda mais a resistência das crianças e dos jovens (com seus corpos "dóceis") ante a investida simbólica da escola, que sem o saber - fazia com que as pulsões dos alunos tivessem seu percurso de satisfação distendido (ao contrário de prontamente satisfeito). E se a 
distensão do percurso de satisfação pulsional é função da Cultura, então a educação deveria ser "tomada dentro do processo civilizatório, como veiculação da cultura, tendo presente sua função essencial de formação" (ibidem, p. 39). Na esteira desse raciocínio, o autor avança sua conclusão sobre o lugar que os ideais educacionais ocupavam em tempos nem tão remotos assim: "Pode-se imaginar que se tratasse da tentativa de resgate de uma função talvez um pouco velha ('moderna' em tempos pós-modernos), mas não vencida: a busca e o resgate de um verdadeiro ideal, no sentido freudiano" (ibidem, p. 39). Kessler assevera ademais que nada há de nostálgico em se recapitular o tempo em que - mesmo no Brasil - a escola pública "rivalizava em qualidade com a escola dita particular": é que além de promover a mistura social, a escola operava como uma instituição pública em que as crianças podiam conviver com iguais, mas também com autoridades.

Eis que a caracterização da escola como dispositivo de controle social - caracterização essa que é menos ou mais enfatizada, de acordo com cada autor - parece depender fundamentalmente do modo como se compreende a reconfiguração das esferas pública e privada que se consumou na modernidade. No primeiro caso, o advento da modernidade é compreendido, primordialmente, como "subversão do espaço público pelo privado" (ibidem, p. 22) e mediante o que se instaurou a já referida parceria entre colégios, Estado e famílias, com o fito de assegurar o ideal utilitarista que gira em torno do desenvolvimento das aptidões individuais das crianças. Ora bem, mas embora tal idéia "de um acordo mais ou menos tácito" - como afirma Narodowski (2001, p. 67) - entre famílias e colégios não seja propriamente inverídica, por outro lado ela não parece dar conta do caráter obrigatório da educação escolar moderna. Afinal, caso não tivesse sido propriamente obrigatória, a escolarização deslanchada pela modernidade então não se teria afrontado com ela o sistema patriarcal. Vejamos, pois, os termos com que Lajonquière (2000, p. 55) coloca a questão:

Assim, os pais foram obrigados a entregar seus filhos à instrução escolar. Em princípio, poder-se-ia observar que se trata de um avanço claro e distinto no sentido do declínio social da figura do pai, comprometedor da eficiência de sua devida função. Porém, parece-nos que se trata, apenas, de um gesto que visa a civilizar a arbitrariedade paterna sobre os destinos dos filhos e cuja permanência em nada acrescentaria à filiação simbólica.

Por fim, talvez não seja inoportuno lembrar aqui que, de acordo com Arendt, na aurora dos tempos modernos, a esfera pública foi elevada a uma nova dignidade (1992, p. 110), o que não foi sem conseqüências 
para a educação (também tornada pública, leiga e obrigatória aî). Restaria ver então se a educação escolar pública originariamente se constituiu como um apêndice narcísico da família (com a sua dita pretensão disciplinadora de desenvolver aptidões) ou se, ao contrário, ela estava à altura de, por exemplo, catalisar a substituição do romance familiar (neurótico) das crianças em nome de uma autêntica narrativa pública: "[...] a criança escolarizada à moda antiga, porém moderna, não só ganha um pai submetido à Lei senão também a possibilidade de ela mesma experimentar em carne própria a submissão ao espírito da consagrada moção revolucionária [liberdade, igualdade e fraternidade]" (LAJONQUIĖRE, 2000, p. 56).

Nesses termos, acreditamos que, muito embora não se deva esquecer que a escola é mesmo prima-irmã dos hospitais, das prisões e da caserna, é preciso lembrar que "a modernidade também lhe reservou atributos singulares" (LAJONQUIĖRE, 1999, p. 82), razão pela qual não se pode reduzi-la unilateralmente a um dispositivo de vigilância e controle do Estado Moderno.

\section{REFERÊNCIAS}

ARENDT, H. Entre o passado e o futuro. Trad. M.W.B. de Almeida. São Paulo: Perspectiva/Petrópolis: Vozes, 1992.

LAJONQUIÈRE, L. Infância e ilusão (psico)pedagógica: escritos de psicanálise e educação. S/l: S/e, 1999.

LAJONQUIÈRE, L. Psicanálise, modernidade e fraternidade. In: KEHL, M. R. (Org.). Função fraterna Rio de Janeiro: Relume Dumará, 2000. p. 51-80.

NARODOWSKI, M. Infância e poder: a conformação da Pedagogia Moderna. Trad. M. Yasbek. Bragança Paulista: Editora da Universidade São Francisco, 2001.

Recebido: $19 / 09 / 08$

Aprovado: 22/10/08

Contato:

LEPSI

Av. da Universidade, 308, Bl A

Cidade Universitária

São Paulo - SP

05508-040 